\title{
Determination of $\mathrm{SCN}^{-}$in Urine and Saliva of Smokers and Non-Smokers by SCN--Selective Polymeric Membrane Containing a Nickel(II)-Azamacrocycle Complex Coated on a Graphite Electrode
}

\author{
Mohammad Reza Ganjali, ${ }^{* 1 \dagger}$ Mohammad YousefI, $* 2$ Mehran JavanbaKht, $* 2$ \\ Tahereh Poursaberi, ${ }^{2}$ Masoud Salavati-NIASARI, ${ }^{3}$ Leila HaJiAgha-BABAEI, ${ }^{* 1}$ \\ Elnaz LATIFI, ${ }^{* 1}$ and Mojtaba SHAMSIPUR ${ }^{* 4}$ \\ *1 Department of Chemistry, Tehran University, Tehran, Iran \\ *2 Department of Chemistry, Tarbiat Modarres University, Tehran, Iran \\ *3 Department of Chemistry, Kashan University, Kashan, Iran \\ *4 Department of Chemistry, Razi University, Kermanshah, Iran
}

\begin{abstract}
The construction, performance characteristics, and application of a novel polymeric membrane coated on a graphite electrode with unique selectivity towards $\mathrm{SCN}^{-}$are reported. The electrode was prepared by incorporating $\mathrm{Ni}$ (II)2,2,4,9,9,11-hexamethyltetraazacyclotetradecanediene perchlorate into a plasticized poly(vinyl chloride) membrane. The influences of membrane composition, $\mathrm{pH}$ and foreign ions were investigated. The electrode displays a near Nernstian slope $\left(-57.8 \mathrm{mV}\right.$ decade $\left.^{-1}\right)$ over a wide concentration range of $1 \times 10^{-7}-1 \times 10^{-1} \mathrm{M}^{\text {of SCN}} \mathrm{SC}^{-}$ion. The electrode has a detection limit of $4.8 \times 10^{-8} \mathrm{M}\left(2.8 \mathrm{ng} / \mathrm{cm}^{3}\right) \mathrm{SCN}^{-}$and shows response times of about $15 \mathrm{~s}$ and $120 \mathrm{~s}$ for low to high and high to low concentration sequences, respectively. The proposed sensor shows high selectivity towards $\mathrm{SCN}^{-}$over several common organic and inorganic anions. The electrode revealed a great enhancement in selectivity coefficients and detection limit for $\mathrm{SCN}^{-}$, in comparison with the previously reported electrodes. It was successfully applied to the direct determination of $\mathrm{SCN}^{-}$in milk and biological samples, and as an indicator electrode in titration of $\mathrm{Ag}^{+}$ions with thiocyanate.
\end{abstract}

(Received February 19, 2002; Accepted May 29, 2002)

The conventional anion-selective electrodes based on quaternary ammonium or phosphonium salts always display the so-called Hofmeister selectivity pattern. ${ }^{1}$ Since the 1980 's, research interest in anti-Hofmeister anion selective membrane electrodes has increased more and more. Recently, electrodes based on derivatives of vitamin $\mathrm{B}_{12}$ and transitional metal complexes of porphyrins, and phthalocyanines have been reported. ${ }^{2-6}$ These electrodes demonstrated potentiometric anion selectivity sequences apparently deviating from the Hofmeister sequences. Such deviations result from the unique interaction of the central metals with an anion rather than from the hydration free energy and the relative solubility of the individual anions in the solvent mediator.

Due to the vital importance of selective $\mathrm{SCN}^{-}$determination, especially in food, biological and water samples, there are several reports on the preparation of $\mathrm{SCN}^{-}$selective membrane electrodes based on a variety of ion carriers. ${ }^{5,7-13}$ However, most of these $\mathrm{SCN}^{-}$sensors have one, two or, in some cases, all of the following problems: a) high detection limit, b) narrow working concentration range and/or c) serious interfering effect of such anions as $\mathrm{ClO}_{4}^{-}$, $\mathrm{I}^{-}$and $\mathrm{IO}_{4}^{-}$.

In this work we report a coated graphite membrane electrode based on $\mathrm{Ni}(\mathrm{II})-2,2^{\prime}, 4,9,9^{\prime}, 11$-hexamethyltetraazacyclotetra-

† To whom correspondence should be addressed.

E-mail: Ganjali@khayam.ut.ac.ir decanediene perchlorate $(\mathrm{NiL})$ for potentiometric monitoring of ultra trace amounts of $\mathrm{SCN}^{-}$.

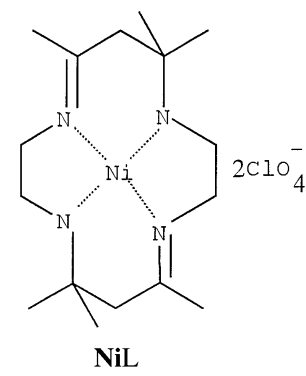

\section{Experimental}

\section{Reagents}

Reagent grade dibutyl phthalate (DBP), benzyl acetate (BA), acetophenone (AP), hexadecyltrimethylammonium bromide (HTAB), tetrahydrofuran (THF), and high relative molecular weight (PVC) were purchased from Aldrich and used as received. Nickel(II)-2,2',4,9,9',11-hexamethyltetraazacyclotetradecanediene perchlorate (NiL) was synthesized and purified as described elsewhere. ${ }^{14}$ Potassium salts of all anions used (all from Merck) were of the highest purity available; they were used without any further purification except for vacuum drying 
Table 1 Optimization of membrane composition

\begin{tabular}{|c|c|c|c|c|c|c|c|c|}
\hline \multirow{2}{*}{$\begin{array}{c}\text { Membrane } \\
\text { No. }\end{array}$} & \multicolumn{6}{|c|}{ Composition, \% } & \multirow{2}{*}{ Slope (mV/decade) } & \multirow{2}{*}{ Linearity range } \\
\hline & PVC & HTAB & AP & DBP & BA & $\mathrm{L}$ & & \\
\hline 1 & 30 & - & - & 70 & - & - & $\sim 2.0$ & - \\
\hline 2 & 30 & - & - & 68 & - & 2 & $\sim 17.5$ & $8.5 \times 10^{-6}-1.0 \times 10^{-1}$ \\
\hline 3 & 30 & - & - & 66 & - & 4 & $\sim 32.1$ & $5.5 \times 10^{-6}-1.0 \times 10^{-1}$ \\
\hline 4 & 30 & - & - & 64 & - & 6 & $\sim 31.5$ & $3.0 \times 10^{-6}-1.0 \times 10^{-1}$ \\
\hline 5 & 30 & - & - & 65 & - & 5 & $\sim 33.7$ & $3.0 \times 10^{-6}-1.0 \times 10^{-1}$ \\
\hline 6 & 30 & - & - & - & 65 & 5 & $\sim 25.8$ & $2.0 \times 10^{-5}-1.0 \times 10^{-1}$ \\
\hline 7 & 30 & 65 & - & - & - & 5 & $\sim 24.7$ & $3.0 \times 10^{-5}-1.0 \times 10^{-1}$ \\
\hline 8 & 30 & - & 1 & 64 & - & 5 & $\sim 43.9$ & $5.0 \times 10^{-7}-1.0 \times 10^{-1}$ \\
\hline 9 & 30 & - & 2 & 63 & - & 5 & $\sim 57.8$ & $1.0 \times 10^{-7}-1.0 \times 10^{-1}$ \\
\hline 10 & 30 & - & 3 & 62 & - & 5 & $\sim 54.1$ & $1.0 \times 10^{-7}-1.0 \times 10^{-1}$ \\
\hline 11 & 30 & - & 2 & - & 63 & 5 & $\sim 40.7$ & $1.0 \times 10^{-6}-1.0 \times 10^{-1}$ \\
\hline 12 & 30 & 63 & 2 & - & - & 5 & $\sim 39.4$ & $1.0 \times 10^{-6}-1.0 \times 10^{-1}$ \\
\hline
\end{tabular}

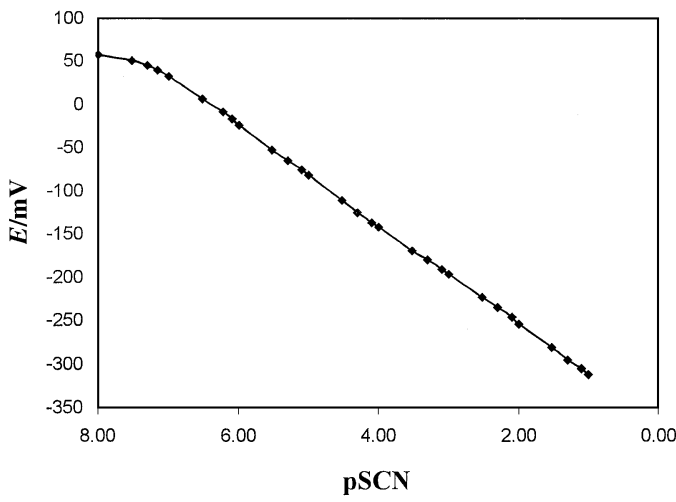

Fig. 1 Calibration graph of $\mathrm{SCN}^{-}$ion-selective electrode.

over $\mathrm{P}_{2} \mathrm{O}_{5}$. Triply distilled deionized water was used throughout.

\section{Electrode preparation}

The PVC membrane solution was prepared by through mixing of ionophore (NiL, $5 \mathrm{mg}$ ), plasticizer (DBP, $63 \mathrm{mg}$ ), additive (HTAB, $2 \mathrm{mg}$ ), and powdered PVC (30 mg), in $5 \mathrm{~cm}^{3}$ of THF. The resulting mixture was transferred into a glass dish of $2 \mathrm{~cm}$ diameter. Graphite electrodes (3 mm diameter and $10 \mathrm{~mm}$ long) were prepared from spectroscopic grade graphite. A shielded copper wire was glued to one end of the graphite rod with epoxy resin, and the electrode was sealed into the end of a PVC tube of about the same diameter by epoxy resin. The working surface of the electrode was polished with fine alumina slurries on a polishing cloth, sonicated in distilled water and dried in air. The polished electrode was dipped into the membrane solution, and the solvent was evaporated. A membrane was formed on the graphite surface, and it was allowed to set overnight. For a comparative study, a membrane containing no active component was also prepared. The electrode was finally conditioned for 24 $\mathrm{h}$ by soaking in a $1.0 \times 10^{-2} \mathrm{M}$ solution of KSCN.

\section{Emf measurements}

All emf measurements were carried out with the following assembly:

Graphite electrode/PVC membrane/sample solution//Hg- $\mathrm{Hg}_{2} \mathrm{Cl}_{2}$, $\mathrm{KCl}$ (satd.)

A Corning ion analyzer $250 \mathrm{pH} / \mathrm{mV}$ meter was used for potential measurements at $25.0 \pm 0.1^{\circ} \mathrm{C}$. The emf observations were made relative to a double-junction saturated calomel electrode (SCE, Philips) with the chamber was filled with an ammonium nitrate solution. Activities were calculated according to the Debye-Hückel procedure. ${ }^{15}$

\section{Results and Discussion}

In order to investigate the selective interaction of the Nil complex, as a potential ion carrier, with different anionic species, the UV/Vis spectra of the complex in the absence and presence of a number of common anions were obtained in acetonitrile solution. The resulting $\mathrm{UV} / \mathrm{V}$ is spectra for $\mathrm{SCN}^{-}$are shown in Fig. 1. From Fig. 1, it is immediately obvious that the addition of ionophore (with two absorption maxima at 220.7 and $278.9 \mathrm{~nm}$ ) to an equimolar solution of $\mathrm{SCN}^{-}$(with two absorption maxima at 213.0 and $232.0 \mathrm{~nm}$ ) will result in simultaneous disappearance of the two $\mathrm{SCN}^{-}$absorptions and increased absorbance of the ionophore maxima. It is interesting to note that the $220.7 \mathrm{~nm}$ band of the ligand has also shifted to $217.5 \mathrm{~nm}$ upon addition of $\mathrm{SCN}^{-}$ion while it increased in absorbance. The observed changes suggest the occurrence of a specific interaction between the ionophore and the anion in solution. At the same time, the effects of other anions on the spectrum of the carrier were investigated. No detectable changes in the corresponding UV/Vis spectra were noted.

The plasticized PVC-based membrane electrode containing ionophore (NiL) generates a stable potential response in solutions containing thiocyanate, after conditioning for about 24 h (Fig. 1). This membrane shows a remarkable selectivity for $\mathrm{SCN}^{-}$over most common inorganic and organic anions. The preferential response towards $\mathrm{SCN}^{-}$is believed to be associated with the coordination of $\mathrm{SCN}^{-}$with the central metal of the carrier.

It is well known that the sensitivity and selectivity obtained for a given ionophore depend significantly on the membrane composition. ${ }^{16-23}$ Thus, the influences of amount of ionophore, nature and amount of plasticizer and nature of additive on the optimal response of the membrane sensor were investigated, while keeping the PVC plasticizer ratio at about 1:2. The results are summarized in Table 1. As is obvious from Table 1, among three different plasticizers used, DBP was found to be the most effective solvent mediator in preparing the $\mathrm{SCN}^{-}$ionselective electrode. The amount of ionophore (NiL) was also found to affect the sensitivity of the membrane electrode. The sensitivity of the electrode's response increased with increasing 


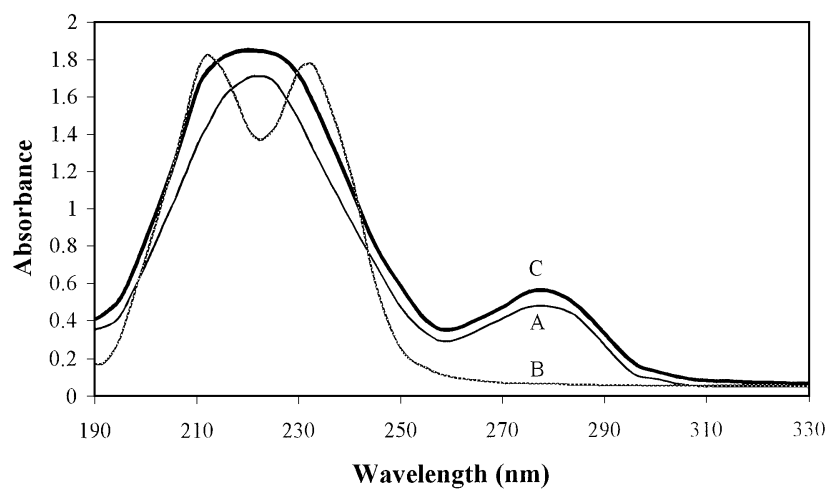

Fig. $2 \mathrm{UV} / \mathrm{Vis}$ absorption spectra of $1.0 \times 10^{-4} \mathrm{M}$ acetonitrile solutions of the ionophore $\mathrm{NiL}(\mathrm{A}), \mathrm{SCN}^{-}(\mathrm{B})$, and ionophore $+\mathrm{SCN}^{-}$ (C).

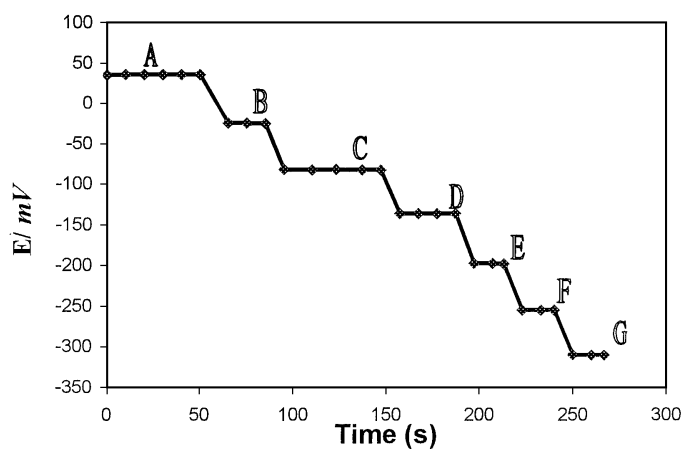

Fig. 3 Dynamic response of $\mathrm{SCN}^{-}$sensor for step changes in concentration of $\mathrm{SCN}^{-}$: A) $1.0 \times 10^{-7} \mathrm{M}$, B) $1.0 \times 10^{-6} \mathrm{M}$, C) $1.0 \times$ $10^{-5} \mathrm{M}$, D) $1.0 \times 10^{-4} \mathrm{M}$, E) $1.0 \times 10^{-3} \mathrm{M}$, F) $\left.1.0 \times 10^{-2} \mathrm{M}, \mathrm{G}\right) 1.0 \times$ $10^{-1}$.

ionophore content until a value of $5 \%$ is reached.

The optimization of permselectivity of membrane sensors is known to be dependent on the incorporation of additional membrane components. In fact, it has been demonstrated that the presence of lipophilic charged additives improves the potentiometric behavior of certain selective electrodes not only by reducing the ohmic resistance ${ }^{25,26}$ and improving the response behavior and selectivity ${ }^{24,27}$ but also, in cases where the extraction capability of the ionophore is poor, by enhancing the sensitivity of the membrane electrode. ${ }^{28}$ Moreover, the additives may catalyze the exchange kinetics to the samplemembrane interface. ${ }^{28}$ The data given in Table 1 revealed that in the presence of a proper additive such as HTAB, the sensitivity of the PVC membrane would improve considerably (No. 8 - 12). As one can see from Table 1, membrane number 9 with a PVC:DBP:L:HTAB percent ratio of 30:63:5:2 results in a near-Nernstian behavior of the membrane electrode over a wide concentration range.

The optimum equilibration time for the membrane electrode in the presence of $1.0 \times 10^{-2} \mathrm{M} \mathrm{KSCN}$ was $24 \mathrm{~h}$, after which it would generate stable potentials in contact with $\mathrm{SCN}^{-}$solution. The electrode shows a linear response to the concentration of $\mathrm{SCN}^{-}$ion in the range of $1.0 \times 10^{-7}$ to $1.0 \times 10^{-1} \mathrm{M}$ (Fig. 1). The slope of the calibration graph was $-57.8 \pm 0.2 \mathrm{mV}$ decade $^{-1}$. The limit of detection, as determined from the intersection of the two extrapolated segments of the calibration graph, was 4.8 $\times 10^{-8} \mathrm{M}\left(\sim 2.8 \mathrm{ng} / \mathrm{cm}^{3}\right)$.

Dynamic response time is an important factor for an $\mathrm{SCN}^{-}$

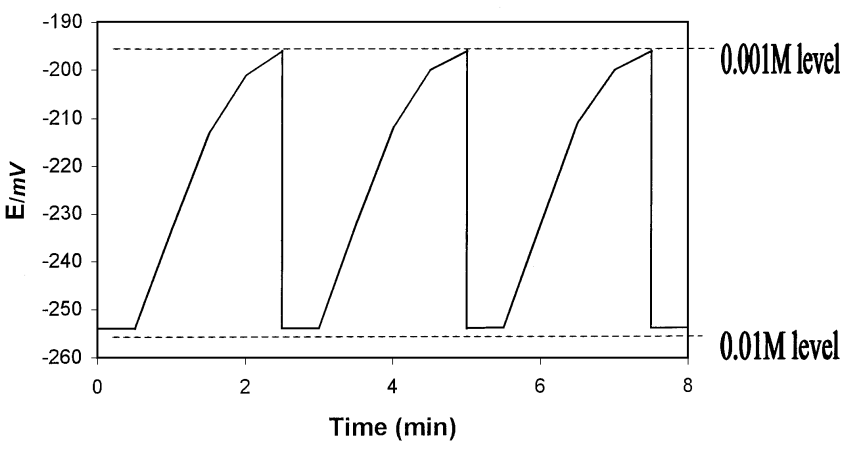

Fig. 4 Dynamic response characteristics of the $\mathrm{SCN}^{-}$electrode for several high-to-low sample cycles.

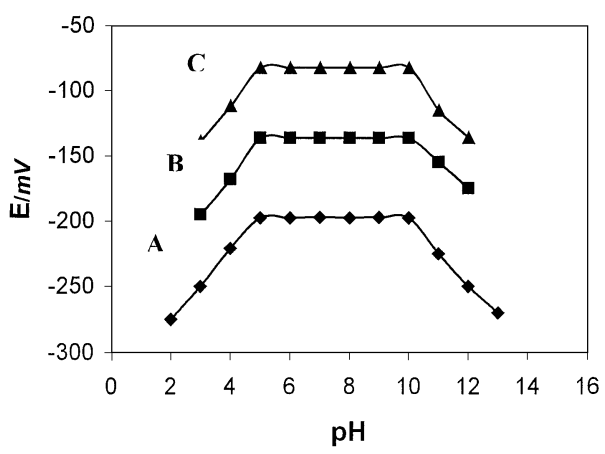

Fig. 5 Effect of $\mathrm{pH}$ of the test solution on the potential response of the $\mathrm{SCN}^{-}$sensor: (A) $1.0 \times 10^{-3} \mathrm{M}$, (B) $1.0 \times 10^{-4} \mathrm{M}$, (C) $1.0 \times 10^{-5}$ M.

sensitive electrode. In this study, the practical response time was recorded by studying solutions with different $\mathrm{SCN}^{-}$ concentrations. The measurement sequence was from the lowto-high (i.e., $1.0 \times 10^{-6}-1.0 \times 10^{-1} \mathrm{M}$ ) and high-to-low concentration (i.e., $1.0 \times 10^{-2}-1.0 \times 10^{-6} \mathrm{M}$ ) and the resulting potential-time traces are shown in Figs. 3 and 4, respectively. While the electrode equilibrium response in about $15 \mathrm{~s}$ (see Fig. 3) for the low-to-high sequence, it possesses a much longer response time of about $120 \mathrm{~s}$ (see Fig. 4), for the high-to-low sequence. A similar response behavior has already been reported in the literature. The actual potential versus time trace is shown in Fig. 3. As one can see, the electrode reaches the equilibrium response in a very short time of about $15 \mathrm{~s}$. To evaluate the reversibility of the electrode, a similar procedure in the opposite direction was adopted. The measurements were performed in the sequence of high-to-low (from $1.0 \times 10^{-2}$ to 1.0 $\times 10^{-6} \mathrm{M}$ ) sample concentrations; the results are shown in Fig. 4 . It is clear that the potentiometric response of the electrode was reversible; although the time needed to reach equilibrium values was longer than that of low-to-high sample concentrations.

The influence of $\mathrm{pH}$ of the test solution $\left(10^{-3}-10^{-5} \mathrm{M}\right)$ on potential response of the membrane sensor was tested in the $\mathrm{pH}$ range 2.0 - 13.0 (adjusted with $\mathrm{H}_{2} \mathrm{SO}_{4}$ and $\mathrm{KOH}$ ) and the results are shown in Fig. 5. As can be seen from Fig. 5, the membrane electrode can be suitably used in the $\mathrm{pH}$ range $5.0-10.0$. However, at higher and lower $\mathrm{pH}$ values a drastic potential changes towards more negative values is observed. This is most probably due to the simultaneous response of the electrode to $\mathrm{SCN}^{-}$and hydroxide, at $\mathrm{pH}>10$, and to $\mathrm{SCN}^{-}$and sulfate (or hydrogen sulfate), at $\mathrm{pH}<4$.

Lifetime studies were based on monitoring the changes in 
Table 2 Stability of the $\mathrm{SCN}^{-}$electrode

\begin{tabular}{|c|c|c|c|c|c|c|c|c|c|}
\hline & 5 & 10 & 15 & 20 & $\begin{array}{c}\text { Time/day } \\
25\end{array}$ & 30 & 40 & 50 & 60 \\
\hline Slope & $57.5 \pm 0.2$ & $57.3 \pm 0.1$ & $57.1 \pm 0.3$ & $57.0 \pm 0.2$ & $56.6 \pm 0.3$ & $56.2 \pm 0.3$ & $56.0 \pm 0.1$ & $55.7 \pm 0.2$ & $55.2 \pm 0.3$ \\
\hline Linearity & $1.0 \times 10^{-7}$ & $1.0 \times 10^{-7}$ & $1.0 \times 10^{-7}$ & $1.0 \times 10^{-7}$ & $1.0 \times 10^{-7}$ & $1.0 \times 10^{-7}$ & $1.0 \times 10^{-7}$ & $1.0 \times 10^{-7}$ & $2.0 \times 10^{-7}$ \\
\hline Range & $1.0 \times 10^{-1}$ & $1.0 \times 10^{-1}$ & $1.0 \times 10^{-1}$ & $1.0 \times 10^{-1}$ & $1.0 \times 10^{-1}$ & $1.0 \times 10^{-1}$ & $1.0 \times 10^{-1}$ & $1.0 \times 10^{-1}$ & $1.0 \times 10^{-1}$ \\
\hline
\end{tabular}

Table 3 Selectivity coefficients of various interfering anions

\begin{tabular}{lcc}
\hline \multicolumn{1}{c}{ Anion } & $K_{\mathrm{SCN}, \mathrm{A}}^{\text {Pot }}(\mathrm{MPM})$ & $K_{\mathrm{SCN}, \mathrm{A}}^{\mathrm{Pot}}(\mathrm{SSM})$ \\
\hline $\mathrm{F}^{-}$ & $3.2 \times 10^{-5}$ & $3.1 \times 10^{-5}$ \\
$\mathrm{Cl}^{-}$ & $4.3 \times 10^{-5}$ & $3.3 \times 10^{-5}$ \\
$\mathrm{Br}^{-}$ & $7.0 \times 10^{-5}$ & $4.9 \times 10^{-5}$ \\
$\mathrm{I}^{-}$ & $2.3 \times 10^{-3}$ & $3.3 \times 10^{-3}$ \\
$\mathrm{~S}_{2} \mathrm{O}_{3}{ }^{2-}$ & $5.9 \times 10^{-5}$ & $4.8 \times 10^{-5}$ \\
$\mathrm{SO}_{3}{ }^{2-}$ & $5.1 \times 10^{-5}$ & $6.9 \times 10^{-4}$ \\
$\mathrm{SO}_{4}{ }^{2-}$ & $3.7 \times 10^{-5}$ & $1.7 \times 10^{-5}$ \\
$\mathrm{HCO}_{3}$ & $8.9 \times 10^{-5}$ & $7.7 \times 10^{-5}$ \\
$\mathrm{CO}_{3}{ }^{2-}$ & $6.6 \times 10^{-5}$ & $8.1 \times 10^{-4}$ \\
$\mathrm{NO}_{2}{ }^{-}$ & $3.1 \times 10^{-4}$ & $7.1 \times 10^{-4}$ \\
$\mathrm{NO}_{3}{ }^{-}$ & $2.2 \times 10^{-4}$ & $5.3 \times 10^{-4}$ \\
$\mathrm{CN}^{-}$ & $1.9 \times 10^{-3}$ & $2.7 \times 10^{-3}$ \\
$\mathrm{ClO}_{4}{ }^{-}$ & $7.1 \times 10^{-4}$ & $6.6 \times 10^{-4}$ \\
$\mathrm{ClO}_{3}{ }^{-}$ & $8.1 \times 10^{-4}$ & $6.8 \times 10^{-4}$ \\
$\mathrm{IO}_{3}{ }^{-}$ & $8.5 \times 10^{-4}$ & $7.9 \times 10^{-4}$ \\
$\mathrm{IO}_{4}{ }^{-}$ & $7.3 \times 10^{-4}$ & $7.0 \times 10^{-4}$ \\
$\mathrm{CrO}_{4}{ }^{2-}$ & $4.5 \times 10^{-5}$ & $7.1 \times 10^{-5}$ \\
$\mathrm{Cr}_{2} \mathrm{O}_{7}{ }^{2-}$ & $3.8 \times 10^{-5}$ & $6.9 \times 10^{-5}$ \\
$\mathrm{MnO}_{4}{ }^{-}$ & $2.9 \times 10^{-5}$ & $1.9 \times 10^{-5}$ \\
$\mathrm{MoO}_{4}{ }^{3-}$ & $2.1 \times 10^{-5}$ & $1.1 \times 10^{-5}$ \\
$\mathrm{Citrate}^{-}$ & $7.5 \times 10^{-5}$ & $7.7 \times 10^{-5}$ \\
$\mathrm{Picrate}^{-}$ & $1.9 \times 10^{-4}$ & $1.3 \times 10^{-5}$ \\
$\mathrm{Salicylate}^{-}$ & $1.3 \times 10^{-4}$ & $8.9 \times 10^{-5}$ \\
$\mathrm{Succinate}^{-}$ & $7.2 \times 10^{-5}$ & $3.9 \times 10^{-5}$ \\
$\mathrm{Oxalate}^{-}$ & $4.1 \times 10^{-5}$ & $2.7 \times 10^{-5}$ \\
$\mathrm{Ascorbate}^{-}$ & $1.8 \times 10^{-4}$ & $2.1 \times 10^{-4}$ \\
\hline
\end{tabular}

electrode slope and linear response range with time; the results are summarized in Table 2. As can be seen, after two months a very slight gradual decrease in slope and linearity range was observed $\left(-55.2 \pm 0.3 \mathrm{mV}\right.$ decade ${ }^{-1}$ and $1.0 \times 10^{-1}-2.0 \times 10^{-7}$ $\mathrm{M}$, respectively).

Potentiometric selectivity coefficient $\left(K_{\mathrm{SCN} . \mathrm{B}}^{\mathrm{Pot}}\right)$ values for the proposed sensor were determined by both the matched potential (MPM) ${ }^{30,31}$ and the separated solution (SSM) methods. ${ }^{32}$ The results are summarized in Table 3. As is clear, there is sufficient agreement between the selectivity coefficients obtained by the two methods. However, the slight difference observed is due to their different experimental procedures (e.g., differences in initial potentials). The selectivity coefficients clearly indicate that the electrode is more selective to $\mathrm{SCN}^{-}$than to a number of other inorganic and organic anions. A typical selectivity pattern for a series anion showed by the electrode is as follows: $\mathrm{SCN}^{-}>\mathrm{I}^{-}>\mathrm{CN}^{-}>\mathrm{IO}_{3}^{-}>\mathrm{ClO}_{3}^{-}>\mathrm{IO}_{4}^{-}>\mathrm{ClO}_{4}^{-}>\mathrm{NO}_{2}{ }^{-}>\mathrm{NO}_{3}{ }^{-}>$Picrate $^{-}>$ Ascorbate ${ }^{-}>$Salicylate $^{-}>\mathrm{HCO}_{3}{ }^{-}>$Citrate $^{-}>$Acetate $^{-}>$Succinate $^{-}>$ $\mathrm{Br}^{-}>\mathrm{CO}_{3}{ }^{2-}>\mathrm{S}_{2} \mathrm{O}_{3}{ }^{2-}>\mathrm{SO}_{3}{ }^{2-}>\mathrm{CrO}_{4}{ }^{2-}>\mathrm{Cl}^{-}>$Oxalate ${ }^{-}>\mathrm{Cr}_{2} \mathrm{O}_{7}{ }^{2-}>\mathrm{SO}_{4}{ }^{2-}>$ $\mathrm{F}^{-}>\mathrm{MnO}_{4}^{-}>\mathrm{MoO}_{4}{ }^{3-}$.

It is interesting to note that the observed selectivity pattern for the proposed sensor significantly differs from the so-called Hofmeister selectivity sequence (i.e. selectivity based solely on lipophilicity of anions). From the data given in Table 3 , it is immediately obvious that the proposed $\mathrm{SCN}^{-}$electrode is highly

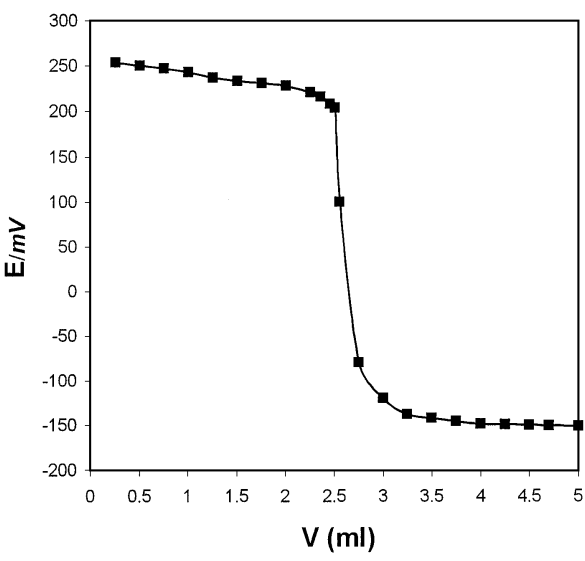

Fig. 6 Potentiometric titration curves of $25 \mathrm{~cm}^{3} 1.0 \times 10^{-4} \mathrm{M}$ silver nitrate with $1.0 \times 10^{-3} \mathrm{M}$ potassium thiocyanate, using the proposed sensor as an indicator electrode.

selective with respect to other inorganic and organic anions. The selectivity coefficients for inorganic and organic anions are in the order of about $10^{-3}$ or smaller. This is most probably due to the weak interaction between these anions and the ionophore.

In Table 4 the selectivity coefficients for the best previously reported $\mathrm{SCN}^{-}$sensors based on different ionophores are compared with those obtained for the proposed electrode. In most cases, the selectivity coefficients obtained for the proposed electrode are superior to those reported for other $\mathrm{SCN}^{-}$ionselective electrodes. It is noteworthy that the limit of detection, linear range and response time of the proposed electrode are also considerably improved with respect to those the previously reported $\mathrm{SCN}^{-}$selective electrodes. $., 7,8,11,12$

A chemical test to distinguish smokers and nonsmokers is important in many epidemiologic studies. ${ }^{33}$ Experimental results have shown that the urinary and salivary $\mathrm{SCN}^{-}$ concentration is higher for smokers than nonsmokers, and so the assay can be used to detect whether or not a person is smoking. However, the $\mathrm{SCN}^{-}$level may vary widely, ${ }^{34}$ depending on the dietary ingestion of the ion. When consumed in excess, some foods contribute to slight elevations in $\mathrm{SCN}^{-}$concentration and these elevations may make it difficult to separation nonsmokers from smokers. Common foods that may contribute to $\mathrm{SCN}^{-}$levels include milk, almonds, garlic, onion, leeks, cabbage and cauliflower.

Taking all of the above results into account, was used the proposed electrode for the following analytical applications. The high degree of $\mathrm{SCN}^{-}$selectivity exhibited by the electrode makes it potentially useful for monitoring concentrations levels of $\mathrm{SCN}^{-}$in biological samples. Table 5 lists $\mathrm{SCN}^{-}$ concentration in milk and human urine and saliva measured by the proposed electrode as well as the reported colorimetric results. As shown, there is a fair agreement between the values obtained by the electrode and the colorimetric methods. 
Table 4 Comparison of selectivity coefficients for different $\mathrm{SCN}^{-}$selective electrodes

\begin{tabular}{|c|c|c|c|c|c|}
\hline \multirow{2}{*}{ Anion } & \multicolumn{5}{|c|}{ Selectivity coefficient } \\
\hline & Ref. 5 & Ref. 7 & Ref. 8 & Ref. 12 & This work \\
\hline Acetate & - & $2.3 \times 10^{-5}$ & $2.3 \times 10^{-5}$ & $3.7 \times 10^{-5}$ & $1.8 \times 10^{-4}$ \\
\hline Azide & - & - & - & $7.9 \times 10^{-3}$ & - \\
\hline Bromide & $4.0 \times 10^{-3}$ & - & $6.7 \times 10^{-4}$ & $5.7 \times 10^{-3}$ & $7.0 \times 10^{-5}$ \\
\hline Carbonate & - & $9.9 \times 10^{-4}$ & $4.1 \times 10^{-4}$ & $1.5 \times 10^{-3}$ & $6.6 \times 10^{-5}$ \\
\hline Chloride & $1.0 \times 10^{-3}$ & - & $9.7 \times 10^{-4}$ & $2.9 \times 10^{-3}$ & $4.3 \times 10^{-5}$ \\
\hline Cyanide & - & - & $5.4 \times 10^{-4}$ & $2.4 \times 10^{-2}$ & $1.9 \times 10^{-3}$ \\
\hline Fluoride & - & - & - & $1.9 \times 10^{-3}$ & $3.2 \times 10^{-5}$ \\
\hline Iodide & $6.3 \times 10^{-3}$ & - & $2.9 \times 10^{-3}$ & $4.9 \times 10^{-2}$ & $2.3 \times 10^{-3}$ \\
\hline Nitrate & - & $5.3 \times 10^{-4}$ & $7.1 \times 10^{-4}$ & $2.1 \times 10^{-3}$ & $2.2 \times 10^{-4}$ \\
\hline Nitrite & - & $1.5 \times 10^{-4}$ & $3.5 \times 10^{-4}$ & $3.7 \times 10^{-3}$ & $3.1 \times 10^{-4}$ \\
\hline Oxalate & - & - & - & $3.7 \times 10^{-5}$ & $4.1 \times 10^{-5}$ \\
\hline Perchlorate & $4.0 \times 10^{-1}$ & $9.8 \times 10^{-3}$ & $9.1 \times 10^{-4}$ & $3.62 \times 10^{-1}$ & $7.1 \times 10^{-4}$ \\
\hline Phosphate & - & - & - & $2.7 \times 10^{-4}$ & - \\
\hline Salicylate & $5.0 \times 10^{-1}$ & $9.0 \times 10^{-4}$ & $1.5 \times 10^{-3}$ & $2.5 \times 10^{-3}$ & $1.3 \times 10^{-4}$ \\
\hline Sulfate & - & $1.5 \times 10^{-5}$ & $5.2 \times 10^{-4}$ & $1.3 \times 10^{-3}$ & $3.7 \times 10^{-5}$ \\
\hline Periodate & $1.0 \times 10^{-1}$ & - & - & - & $7.3 \times 10^{-4}$ \\
\hline
\end{tabular}

Table 5 Determination of $\mathrm{SCN}^{-}$in different samples

\begin{tabular}{lcc}
\hline \multirow{2}{*}{\multicolumn{1}{c}{ Sample }} & \multicolumn{2}{c}{$\mathrm{SCN}^{-/} / \mathrm{mmol} \mathrm{L}^{-\mathrm{la}}$} \\
\cline { 2 - 3 } & Electrode $^{\mathrm{b}}$ & Colorimetric method \\
\hline Nonsmoker's urine & $0.26 \pm 0.06$ & $0.27 \pm 0.04$ (Ref. 35) \\
Smoker's urine & $0.73 \pm 0.06$ & $0.72 \pm 0.06$ (Ref. 35) \\
Nonsmoker's saliva & $0.62 \pm 0.05$ & $0.61 \pm 0.04$ (Ref. 36) \\
Smoker's saliva & $1.82 \pm 0.08$ & $1.83 \pm 0.06$ (Ref. 36) \\
Pooled bovine milk & $0.042 \pm 0.004$ & $0.043 \pm 0.003$ (Ref. 37) \\
Skim milk & $0.027 \pm 0.001$ & $0.028 \pm 0.001$ (Ref. 37) \\
\hline
\end{tabular}

a. Mean value \pm standard deviation (three determinations). b. Samples were diluted 1:10 and adjusted to $\mathrm{pH} 5.0$ with phosphoric acid and potassium hydroxide solutions. Calibration plots were obtained under the same experimental conditions.

The sensor was also successfully applied as an indicator electrode for the potentiometric titration of silver ion with $\mathrm{SCN}^{-}$ solution (Fig. 6). The amount of $\mathrm{Ag}^{+}$ion $(1.0 \pm 0.05) \times 10^{-4}$ can be accurately determined by the electrode. The RSD for ten replicate measurements over five days is $5 \%$.

\section{Acknowledgements}

The authors express their appreciation to the Tehran University Research Council for financial support of this work.

\section{References}

1. F. Hofmeister, Arch. Exp. Pathol. Pharmacol., 1888, 24, 247.

2. S. Daunert and L. G. Bachas, Anal. Chem., 1989, 61, 499.

3. O. Schulthess, D. Ammann, B. Krantler, C. Caderas, R. Stepinek, and W. Simon, Anal. Chem., 1985, 57, 1379.

4. R. Stepinek, B. Krantler, O. Schulthess, B. Lindemann, D. Ammann, and W, Simon, Anal. Chim. Acta, 1986, 182, 83.

5. D. Gao, J. Z. Li, and R. Q. Yu, Anal. Chem., 1994, 66, 2245.

6. S. Daunert, S. Wallace, A. Florido, and L. G. Bachas, Anal.
Chem., 1991, 63, 1676.

7. T. Poursaberi, M. Salavati-Niasari, S. Khodabakhsh, L. Haji-agha Babaei, M. Shamsipur, M. Yousefi, S. Rouhani, and M. R. Ganjali, Anal. Lett., 2001, 34, 2621.

8. M. R. Ganjali, T. Poursaberi, F. Basiripour, M. SalavatiNiasari, M. Yousefi, and M. Shamsipur, Fresenius J. Anal. Chem., 2001, 370, 1091.

9. S. S. M. Hassan and M. A. M. F. Elmosalamy, Analyst, 1987, 112, 1709.

10. A. Hodinar and A. Jyo, Chem. Lett., 1988, 993.

11. Z. Q. Li, Z. Y. Wu, R. Yuan, M. Ying, G. L. Shen, and R. Q. Yu, Electrochim. Acta, 1999, 44, 2543.

12. M. K. Amini, S. Shahrokhian, and S. Tangestaninejad, Anal. Chim. Acta, 1999, 402, 137.

13. M. K. Amini, S. Shahrokhian, and S. Tangestaninejad, Anal. Lett., 1999, 32, 2737.

14. N. F. Curtis, Y. M. Curtis, and H. K. J. Powell, J. Chem. Soc. A, 1966, 1015.

15. S. Kamata, A. Bhale, Y. Fukunaga, and A. Murata, Anal. Chem., 1998, 60, 2464.

16. M. Shamsipur, S. Rouhani, M. R. Ganjali, H. Eshghi, and H. Sharghi, Sens. Actuators B, 1999, 59, 30.

17. M. Shamsipur, M. Yousefi, and M. R. Ganjali, Anal. Chem., 2000, 72, 2391.

18. A. R. Fakhari, M. R. Ganjali, and M. Shamsipur, Anal. Chem., 1997, 69, 3693.

19. M. R. Ganjali, A. Moghimi, and M. Shamsipur, Anal. Chem., 1998, 70, 5259.

20. S. B. Park, W. Matuszewski, M. E. Meyerhoff, Y. H. Liu, and K. M. Kadish, Electroanalysis, 1991, 3, 909.

21. P. C. Hauser, Anal. Chim. Acta, 1993, 278, 227.

22. S. Nomura, Analyst, 1995, 120, 1503.

23. S. Ozawa, H. Miyagi, Y. Shibata, N. Oki, T. Kunitake, and W. E. Keller, Anal. Chem., 1996, 68, 4149.

24. T. Rosatzin, E. Bakker, K. Suzuki, and W. Simon, Anal. Chim. Acta, 1993, 280197.

25. D. Ammann, E. Pretsch, W. Simon, E. Lindner, A. Bezegh, and E. Pungor, Anal. Chim. Acta, 1991, 171, 1380.

26. U. Schaller, E. Bakker, U. E. Spichiger, and E. Pretsch, Anal. Chem., 1994, 66, 391.

27. R. Eugster, P. M. Gehrig, W. E. Morf, U. Spichiger, and W. Simon, Anal. Chem., 1991, 63, 2285. 
28. M. Gehrig, W. E. Morf, M. Welti, E. Pretsch, and W. 33. W. C. Butts, M. Kuehneman, and G. M. Widdowson, Clin. Simon, Helv. Chim. Acta, 1990, 73, 203. Chem., 1974, 20, 1344.

29. Y. Umezawa, K. Umezawa, and H. Sato, Pure Appl. 34. R. Gmelin and I. Virtanen, Acta Chim. Scand., 1962, 16, Chem., 1995, 67, 507.

30. E. Bakker, Electroanalysis, 1997, 9, 7. 1378.

31. V. P. Gadzepko and G. D. Christian, Anal. Chim. Acta, 1984, 164, 279.

35. T. G. Whiston and G. W. Cherry, Analyst, 1962, 87, 819.

K. P. Xiao, P. Bühlmann, S. Nishizawa, S. Amemiya, and Y. Umezawa, Anal. Chem., 1997, 69, 1038.

6. M. Z. Sato, M. J. Diaz, K. S. Nevermann, and A. Perez, Acta Bioquim. Clin. Lantinoamer., 1998, 32, 39.

37. L. Partanen, K. Valkonen, and T. Alatossava, Milchwissenschaft-Milk Sci. Intern., 1998, 53, 132. 